\title{
A comparative study on travel mode share, emission, and safety in five Vietnamese Cities
}

\author{
An Minh Ngoc ${ }^{1,3} \cdot$ Hiroaki Nishiuchi ${ }^{1} \cdot$ Nguyen Van Truong $^{2,3} \cdot$ Le Thu Huyen $^{3}$
}

Received: 17 June 2021 / Revised: 11 October 2021 / Accepted: 14 October 2021 / Published online: 21 October 2021

(c) The Author(s), under exclusive licence to Intelligent Transportation Systems Japan 2021

\begin{abstract}
Motorcycles dominate current transport activities in Vietnamese cities; however, historical data show that bikes and public transport were popular as recently as 30 years ago. Because the transport infrastructure in Vietnamese cities makes it unsafe for cycling and inconvenient for public transport, many cyclists and public transport users switch to private motorized vehicles, particularly motorcycles, as soon as they can afford to make the change. The preference for motorcycles in Vietnamese cities has resulted in an increased risk of road traffic accidents and a degradation of air quality. Reducing the share of motorcycles on Vietnamese roads by improving public transport would be expected not only to improve public safety but also to have a positive impact on the environment and public health. However, efforts to improve the public transport have not yet been properly integrated into the local government system in every city. As the result, each city has different outcomes in mitigating the motorcycle-related challenges. This study examines travel behaviors in five major Vietnamese cities-Hanoi, Hai Phong, Da Nang, Ho Chi Minh City (HCMC), and Can Tho-and compares the impact of improved public transport on mode choice, emissions, and traffic safety. It is found that improving public transport would result in an 21.11 percent reduction in transport emissions by 2030 in Hanoi, as well as reductions of 12.5 percent in Hai Phong, 17.37 percent in Da Nang, 9.75 percent in HCMC, and 15.21 percent in Can Tho. The differences in these percentages are due to the heterogeneous modal shifts among cities. The provision of improved public transport is also shown to reduce the risk of road traffic accidents. The risk of a traffic fatality in Hanoi decreases by 49.6 percent, while in Hai Phong, the reduction is 43.8 percent; the risk in Can Tho, Da Nang and HCMC decreases by 18.7 percent, 19.8 percent, and 26.3 percent, respectively. As public transport investment is beginning to be adapted to the city context, our results indicate that investment capital on improving the public transport system would partly contribute on reducing emissions and traffic accidents in Vietnamese cities.
\end{abstract}

Keywords Vietnamese city $\cdot$ travel mode share $\cdot$ emissions $\cdot$ safety

An Minh Ngoc

an.ngoc@kochi-tech.ac.jp

Hiroaki Nishiuchi

nishiuchi.hiroaki@kochi-tech.ac.jp

Nguyen Van Truong

ngvtruong@utc.edu.vn

Le Thu Huyen

lethuhuyen@utc.edu.vn

1 School of Systems Engineering, Kochi University of Technology, 185 Tosayamadacho-Miyanokuchi, Kami City, Kochi 782-8502, Japan

2 Department of Tourism Science, Tokyo Metropolitan University, 1-1 Minami-Osawa, Hachioji-City, Tokyo 192-0397, Japan

3 University of Transport and Communications, 3 Cau Giay, Lang Thuong, Dong Da, Hanoi 100000, Vietnam

\section{Introduction}

Motorcycles dominate the daily travel patterns in Vietnam. Motorcycle ownership has increased rapidly over the last three decades, with over 65 million motorcycles operating in 2020 compared to 1.2 million in 1990 [30]. During the same period, ownership of private cars has also risen, from 60,000 to 2.2 million.

With the growth of the vehicular fleet and the increased usage of motorized vehicles resulting from the rapid expansion of the country's economy, traffic risks and fuel consumption by road transport have increased dramatically. Over the two decades from 1990 to 2010, traffic fatalities in Vietnam increased more than five times [29], while final annual energy consumption in the transport sector increased at a rate of 8.8 percent [31]. In 2014, transport accounted for 
an estimated 18 percent of the total greenhouse gas (GHG) emissions of the energy sector [16]. The relatively high level of $\mathrm{CO}_{2 \mathrm{e}}$ emissions from the transport sector has been linked to the high mode share of private vehicles. In this context, the unique challenges related to motorcycles have attracted the attention of policymakers and researchers, pushing them to intensify efforts to reduce motorcycle-related accidents and emissions. Studies have suggested various solutions to reduce motorcycle usage, including the promotion of public transit $[12,32,33,40]$, increasing travel time by motorcycles in relationship with those by public transit [10], and raising parking fees [10, 39]. However, it has been argued that such solutions are not likely to significantly reduce motorcycle use as the travel behavior of motorcyclists is well-established, and the motorcyclists are often unwilling to switch to other modes [7]. If this is indeed the case, motorcycles will continue to play a significant role in the lives of residents seeking ways to improve their mobility.

Despite the rather gloomy prospect of ongoing environmental pollution and worsening traffic security, there remain some bright spots, particularly with regard to policy interventions aimed at reviving the public transport system. In the 2000s, Hanoi launched an aggressive program designed to substantially improve its nearly extinct bus system by establishing new bus routes, investing in a new vehicle fleet, modernizing the bus infrastructure and making passenger information easier to access. Within three years of the program's introduction, ridership had increased to a level three times that of its prior peak in 1980 (Fig. 1). Importantly, Hanoi's experience demonstrates that providing a modern and efficient public transport service to citizens can help curb increasing emission levels and promote public safety.

Such transport interventions facilitate changes in travel choice, including mode choice and activity choice, which, in turn, can provide both direct and indirect benefits, potentially reducing safety risks to road users and improving the air quality of the region. At present, numerous studies have been conducted to explore the influence of transport

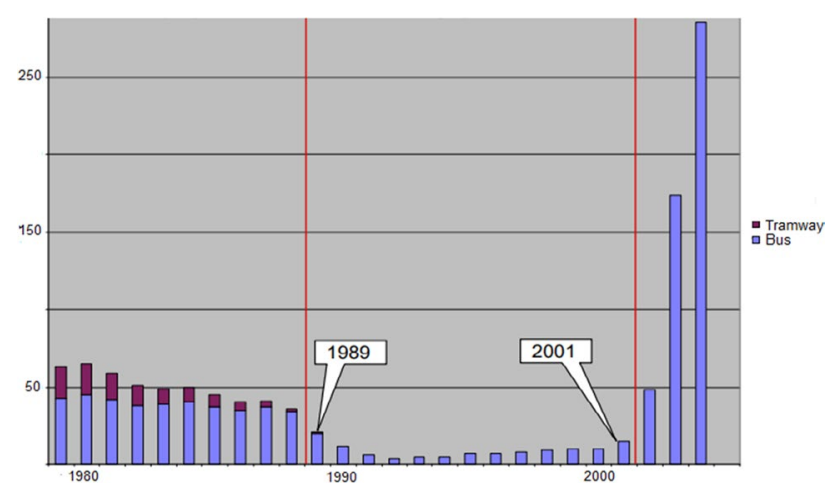

Fig. 1 Public transport ridership in Hanoi, 1979-2005 interventions on mode choice [1, 13, 36-38]. For example, shared mobility intervention may promote reduced household vehicle ownership and increase the use of active transportation modes [36]. As a part of such interventions, providing pertinent information can further encourage people to choose an active travel mode [2]. In particular, access to information related to traffic conditions and fuel cost has been shown to impact mode share, energy saving and new car sales [5, 6, 45]. Aggressive measures such as banning motorcycles have been associated with an increase in the use of environmentally-friendly modes [46] or a switch to automobiles [18, 27]. Many scholars reveal that public transport should be the best choice due to its overall impacts on sustainable transport. Public transport encourages active travel modes and eliminates the use of private modes [26]. Furthermore, public transport like buses promotes social equity because it fulfills the mobility needs of low-income groups [4, 14]. However, many South-East Asian countries, including Vietnam, face the challenges of promoting public transport due to a lack of investment and limited financial resources [34]. Other studies also confirmed that high dependence on motorcycles might be an obstacle for active travel and public transport development in South-East Asian countries $[3,20]$.

To address the motorcycle-related challenges in Vietnamese cities, there is a need to evaluate the nature and impact of shifting mode choice. As a starting point, mode share needs to be assessed for the current fleet in order to make meaningful before-and-after comparisons.

Improvement of public transport is determined to have influence on mode choice and then to reduce emission and accident in developing countries. However, a comparative study of mode choice shift and its consequence on emission and safety has been rarely investigated in developing countries or in such cities with high motorcycle domination as Vietnamese cities. The present study has attempted to examine and compare the potential influences on mode choice outcomes across cities, providing deeper insights how mode choice might change with different strategies in public transport. Vietnamese cities are facing with high rate of motorcycle-related accidents and increasing air pollution; thus, identification and quantification of mode share in the cities with high rate of motorcycles is essential to be taken into consideration. The present study has focused on exploring the differences in mode share and the link between emission, safety, and the mode share in the Vietnamese context.

The five cities selected for the study are considered the economic/business centers of Vietnam. They not only play the most important role in government administration, but they also function as transport hubs in Vietnam's regional transport system. The five cities have been growing rapidly, with high rates of motorization, and require appropriate policy interventions to ensure sustainable development 
and low carbon mobility. With their different geographic locations and population sizes, these cities provide a sound basis for understanding the range of variation in travel behavior and the different types of measures that will need to be instituted.

The remainder of this article is organized as follows: First, the methodology and data sources are described. Next, transport activities, emissions levels, and safety indicators for the five selected cities are detailed. The effect of changes in the public transport and service quality on mobility and transport emissions is then discussed, along with the impact of such changes on traffic safety. A summary of the study and its conclusions is provided in the final section.

\section{Methodology and Data Sources}

\subsection{Travel demand and mode share estimation}

Daily travel demand in five selected cities was estimated using relevant growth rates and the results of household interviews and other various transportation surveys. The predictor formula is shown as follows.

$\operatorname{Trip}_{t}=T R_{t} * P_{t}=T R_{o} *(1+G) * P_{t}$

Where:

Trip: :Total trips in year $t$

$T R_{o}, T R_{t}:$ Trip rate in base year and in year $t$

$P_{t}:$ Population in year $t$

G: Growth rate (i.e. trip rate).

$G=e * P_{G}$

e: Elasticity of transport indicator (see Eq. (3))

$P_{G}$ : Population growth rate

Mode share in baseline (BAU) was also calculated with an elasticity index. Transport elasticity is a measure of the percentage change in travel demand with respect to the percentage change in the selected economic indicator. That is:

$e=\frac{\text { Perentage change in transport indicator }}{\text { Percentage change in economic indicator }}$

In Eq. (2) and (3), we estimated transport demand elasticity values and future growth rate for eight transportation modes. The estimated number of vehicles was then multiplied by the occupancy rate to obtain the mode share for each mode in the baseline case. Sum of mode share obtained would compare with the total travel demand in Eq. (1) to adjust the share of each mode with simple adjustment factor.

Mode share shift under policy interventions was estimated by a logistic function of generalized travel cost as follows:
$P_{m}=\frac{1}{1+e^{\alpha C_{m}+\beta}}$

$C_{m}=t_{m} * V O T_{m}+\frac{d_{i j} * V O C_{m}+P C_{m}}{O P_{m}}$

where

$P_{m}:$ Probability of choosing mode $m$

$C_{m}:$ Generalized cost of mode $m$

$t_{m}$ : Travel time of mode $m$

$V O T_{m}$ : Value of time of user of mode $m$

$V O C_{m}$ : Vechicle operating cost of mode $m$ (for bus and public transport, fare)

$P C_{m}$ : Parking cost of mode $m$

$O P_{m}:$ Average occupancy of mode $m$

$\alpha, \beta$ : Parameter

\subsection{Emission estimation}

Emissions were quantified using a bottom-up approach. The amount of GHG emissions caused by motorized transport depends, on the one hand, on the extent of transport activities. On the other hand, it depends on the specific energy consumption of the transportation mode and on the specific emissions of the final energy carriers. The emissions included in the study are GHG emissions and local pollutants, including particulate matter $\left(\mathrm{PM}_{2.5}\right), \mathrm{NO}_{\mathrm{X}}$, and $\mathrm{SO}_{2}$. GHG includes direct emissions (tank-to-wheel or TTW) and indirect emissions (well-to-tank or WTW), as indicated below:

$E F_{k m, i, W T W}=E F_{k m, i, T T W} \times U E F_{i}+B C_{z}$

where:

$E F_{k m, i, W T W}:$ Well-to-wheel emission factor per kilometer of vehicle using fuel type $i(\mathrm{gCO} / \mathrm{km})$

$E F_{k m, i, T T W}:$ Tank-to-wheel emission factor per kilometer of vehicle using fuel type $i(\mathrm{gCO} 2 \mathrm{em})$

$U E F_{i}$ : Upstream emission factor for fuel type $i$

$B C_{z}$ : Black Carbon emission of vehicle type $z\left(\mathrm{gCO}_{2} \mathrm{~km}^{\mathrm{k}}\right)$

$B C_{z}=P M_{2.5, z} \times B C F_{2.5, z} \times G W P_{B C}$

where:

$B C_{z}$ : Black Carbon emission of vehicle type z $(\mathrm{gCO} 2 \mathrm{CO} \mathrm{km})$

$P M_{2.5, z}: P M_{2.5}$ emissions of vehicle type $z(\mathrm{~g} / \mathrm{km})$

$B C F_{2.5, z}:$ Black Carbon fraction in $P M_{2.5}$ emissions of vehicle type $z(\%)$

$G W P_{B C}:$ Global Warming Potential of Black Carbon (no unit)

For electric vehicles, WTW emissions include the emissions caused by electricity production, transmission and losses. 
$E F_{k m, \text { elec }, W T W}=S E C_{k m} \times G F_{\text {elec }} \times 10^{3}$

where:

$E F_{\text {km,elec,WTW: Well-to-wheel emission factor per kilometer }}$ of electric vehicle $\left(\mathrm{gCO}_{2 e} / \mathrm{km}\right)$

$S E C_{k m}$ : Specific electricity consumption per kilometer of electric vehicle $(\mathrm{kWh} / \mathrm{km})$

$\mathrm{GF}_{\text {elec }}$ : Carbon grid factor of electric grid $\left(\mathrm{kgCO}_{2} / \mathrm{kWh}\right)$

In the updated NDC, the projections use 2014 as the base year, with estimates to 2030 . Since all surveys were conducted in (or around) 2014 in the five selected cities, 2014 was set as the base year for this study.

\subsection{Safety indicator estimation}

A simple model was used to project the number of fatalities:

$$
\operatorname{Ln}\left(F R_{100,000}\right)=b_{1}+b_{2} * \ln \left(M C_{1000}\right)+b_{3} * \operatorname{Ln}\left(\operatorname{Car}_{1000}\right)
$$

where

$F_{100,000}:$ Rate of road traffic fatalities per 100,000 inhabitants

$M C_{1000}$, Car $_{1000}:$ Motorcycle and car per 1,000 inhabitants

\section{b1, b2, b3 Parameters}

Equation (8) allows the application multiple least-squares regression. To eliminate exhibited autocorrelation, heteroscedasticity and non-normality, diagnostic checking was used, including the Lagrange Multiplier test for serial correlation $[8,15]$ and the White test for heteroscedasticity [42].

\subsection{Data sources and data processing}

This study was conducted based on household travel database acquired from the Department of Transport and other sources. The household travel database contains three main categories: (i) individual and household characteristics; (ii) workday travel diary; and (iii) the stated travel mode shift response after the improvement of public transport system.

Table 1 shows the various household travel data at the city level.

Since the cities conducted their surveys at different times, all values were converted to a common point in time to ensure greater consistency in the data analysis. In this study, 2014 was selected as the base year. Accordingly, the data were converted to 2014 values using the average growth for two years for which data were available. Because data for Haiphong were not available, the mean value for Da Nang and Can Tho for reference. Table 2 shows an example of the estimated trip rates.

To estimate the mode shares in 2014, the occupancy rate taken from the household travel surveys was multiplied by the number of registered vehicles. In the case of Hai Phong, the
Table 1 Transport activity surveys at the city level

\begin{tabular}{lll}
\hline & Fund/characteristics & Sample \\
\hline Hanoi & JICA - HIS, 2005 & 20,000 households \\
& JICA - HIS, 2015 & 18,000 households \\
& Hanoi PC - HIS, 2017 & 9,121 households \\
Hai Phong & JICA - 2015 & N/A \\
Da Nang & World Bank - HIS, 2012 & 1,200 household \\
& Da Nang PC - HIS, 2018 & 3000 household \\
Ho Chi Minh City & JICA - HIS, 2003 & 20,000 household \\
& JICA- HIS, 2015 & 20,000 household \\
Can Tho & HCMC DOT - HIS, 2018 & 9,000 household \\
& Can Tho PC - HIS, 2013 & 6,210 persons \\
& World Bank - HIS, 2020 & 2,000 household \\
\hline
\end{tabular}

Table 2 Trip rates in five cities, converted to 2014

\begin{tabular}{|c|c|c|c|c|c|}
\hline & Hanoi & Hai Phong & Da Nang & $\mathrm{HCMC}$ & Can Tho \\
\hline \multicolumn{6}{|c|}{ Trip rate observed between two years availability } \\
\hline 2012 & & & 2.29 & & \\
\hline 2013 & 2.9 & & & 2.77 & 1.93 \\
\hline 2017 & 3.15 & & & & \\
\hline 2018 & & & 2.98 & 3.0 & \\
\hline 2020 & & & & & 2.26 \\
\hline \multicolumn{6}{|c|}{ Corresponding Population } \\
\hline 2012 & & & 966.3 & & \\
\hline 2013 & 6,977 & & & 7,820 & 1,229 \\
\hline 2017 & 7,661 & & & & \\
\hline 2018 & & & 1,081 & 8,843 & \\
\hline 2020 & & & & & 1,241 \\
\hline Elasticity & 1.13 & & 0.42 & 1.54 & 0.06 \\
\hline Trip rate 2014 & 3.04 & 2.2 & 2.5 & 2.8 & 1.97 \\
\hline
\end{tabular}

Household travel survey data

average occupancy rate in Da Nang and Can Tho was used to estimate the mode-specific travel demand. When making these estimates, it was assumed that the occupancy rate would remain constant over time. Finally, a simple adjustment was made to ensure that the sum of the mode-specific travel demands was equal to the total estimated travel demand. The final results are described in Section 3.1.

For the emissions model, statistical data, which included fleet stock, vehicle lifecycle, fuel consumption and traffic collision data, were used to calculate the required outputs. These data were collected from sources such as the National Traffic Safety Committee (NTSC), the Traffic Police Bureau, and the Vietnam Register (VR). 


\section{Mobility, environment and safety indicators in period 2014-2020 in five major Vietnamese cities}

\subsection{Travel demand and mode share}

Based on the converted data, the total daily travel demand in the five cities for the base year 2014 was estimated to be 53,428 trips/day (excluding walking trips). Travel demand increased to 66,917 trips/day in 2020 (Fig. 2).

In general, travel demand incr

eases are a function of increases in population and increases in trip rates. Here, average travel demand increased by 2.5 percent annually, while the average population growth rate was approximately 1.9 percent, and the average growth rate of the trip rate was approximately 2.94

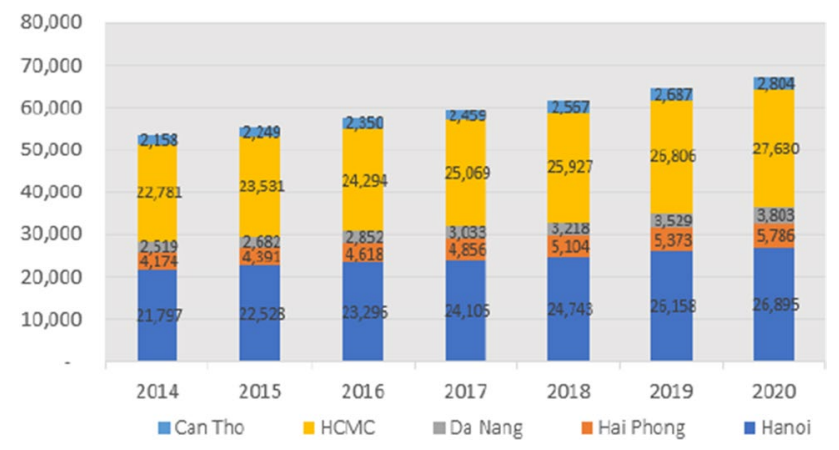

Fig. 2 Number of trips in the five cities, 2014-2020 percent. The estimated mode shares are shown in Table 3 and can be summarized as follows:

(i) The share of trips made by motorcycle accounted for 85-87 percent of the total demand between 2014 and 2020 .

(ii) The share of "car" trips comprised 5-9 percent of total demand; the number of trips made by car increased by 200 percent between 2014 and 2020 .

(iii) The number of trips made by bus decreased and the modal share dropped from 3.6 percent, on average, in 2014 to 2.7 percent in 2020. Modal share was highest in Hanoi, with 10.3 percent in 2014, but fell to 8.6 percent in 2020. Similarly, bus share in HCMC decreased from 6.1 percent to 4.7 percent.

(iv) The number of trips made by bike decreased by 97 percent between 2014 and 2020; the share of trips made by bike accounted for 4.6 percent and 2.9 percent of the total demand in 2014 and 2020, respectively.

Average trip lengths and travel times differ by travel mode. Based on the survey data, in Hanoi, bikes are used mainly within a $2 \mathrm{~km}$ distance; motorcycles are mostly used within a $10 \mathrm{~km}$ distance, with an average trip length of 5 $\mathrm{km}$ and an average travel time of 19 minutes; the average trip length and average travel time for cars are $9.1 \mathrm{~km}$ and 30 minutes, respectively; taxis are used in a similar way as cars, although taxi travel is longer than that of cars; buses are used for relatively longer distances, with an average trip length of $12 \mathrm{~km}$ and an average travel time of 41 minutes.
Table 3 Modal share summarized for the five cities between 2014 and 2020 (Unit: $\%)$

\begin{tabular}{lllllll}
\hline 2014 & & Hanoi & Hai Phong & Da Nang & HCMC & Can Tho \\
Private & Bike & 4.8 & 7.8 & 2.6 & 4.3 & 3.2 \\
& MC & 72.6 & 79.5 & 88.9 & 82.0 & 85.0 \\
\multirow{3}{*}{ Para-transit } & PC & 6.0 & 2.5 & 1.8 & 3.4 & 3.1 \\
& MC taxi & 2.9 & 9.1 & 4.2 & 3.4 & 7.6 \\
PT & Taxi & 3.4 & 0.6 & 1.1 & 0.7 & 0.3 \\
& Bus & 10.3 & 0.5 & 0.4 & 6.1 & 0.6 \\
& BRT & - & - & - & - & - \\
Private & Metro & - & - & - & - & - \\
& & Hanoi & Hai Phong & Da Nang & HCMC & Can Tho \\
& Bike & 3.5 & 2.8 & 1.9 & 4.3 & 1.9 \\
Para-transit & MC & 72.6 & 79.4 & 85.9 & 80.7 & 85.9 \\
& PC & 6.9 & 7.3 & 7.5 & 3.4 & 7.5 \\
PT & MC taxi & 2.9 & 7.3 & 2.5 & 3.4 & 2.5 \\
& Taxi & 6.4 & 2.7 & 0.8 & 3.6 & 0.4 \\
& Bus & 8.6 & 0.1 & 0.2 & 4.7 & 0.1 \\
& BRT & 0.2 & - & - & - & -
\end{tabular}


In HCMC, if intra-zonal trips are taken into account, the respective average trip lengths by bike, motorcycle and car are $1.9 \mathrm{~km}, 3.3 \mathrm{~km}$ and $6.8 \mathrm{~km}$; when intra-zonal trips are excluded, the average trip lengths are considerably longer, at $5.3 \mathrm{~km}, 6.7 \mathrm{~km}$ and $9.7 \mathrm{~km}$, respectively. In Can Tho, trips by motorcycle or private car, as well as by taxi, typically have an average trip time of less than 20 minutes; trips by bus are longer, with up to 45 percent of the trips by bus having a travel time of 50 to 60 minutes. Because data on trip length and travel time in Hai Phong and Da Nang were not available, the data for Can Tho are used for reference.

\subsection{Fuel consumption by vehicle fleet}

Car fleet characteristics were determined from the Vietnam Register. Table 4 shows the share of cars by fuel used.

As there are no mandatory tests for motorcycles, e-motorcycles, e-bikes and regular bikes, only data on the number of motorcycles, e-motorcycles, bikes and e-bikes that had, at some point, been registered are available (from the Police Bureau). In order to analyze the percentage of motorcycles still in use versus the overall number of registered motorcycles, a dataset from MOT [28] at the country level was used (Table 5). Between 2014 and 2018, the survival rate of motorcycles was 70.2 percent. This percentage was applied to the five cities to estimate the actual number of motorcycles circulating (i.e., in use) in each of the cities.

\subsection{Emissions}

Emissions associated with transport have become a major source of pollution in urban areas. In this study, the approach

Table 4 Vehicle fleet by fuel type in the five cities, 2020 (Unit: \%)

\begin{tabular}{llllll}
\hline \multirow{5}{*}{ Hanoi } & & Gasoline & DO & CNG & Electric \\
& PC & 90 & 10 & - & - \\
\multirow{5}{*}{ Hai Phong } & Taxi & 100 & - & - & - \\
& Bus & - & 92.3 & 7.7 & - \\
& PC & 90 & 10 & - & - \\
& Taxi & 100 & - & - & - \\
\multirow{5}{*}{ Da Nang } & Bus & - & 100 & - & - \\
& PC & 90 & 10 & - & - \\
& Taxi & 100 & - & - & - \\
HCMC & Bus & - & 100 & - & - \\
& PC & 90 & 10 & - & - \\
& Taxi & 100 & - & - & - \\
\multirow{5}{*}{ Can Tho } & Bus & - & 78.9 & 21.1 & - \\
& PC & 90 & 10 & - & - \\
& Taxi & 100 & - & - & - \\
& Bus & - & 100 & - & - \\
\hline
\end{tabular}

Vietnam Register, 2020b
Table 5 Survival rate of motorcycle

\begin{tabular}{llll}
\hline Year & Registered MC & MC in circulation & Survival rate \\
\hline 2010 & $31,452,503$ & $21,473,102$ & $68.3 \%$ \\
2011 & $33,925,839$ & $23,998,149$ & $70.7 \%$ \\
2012 & $36,102,943$ & $26,605,882$ & $73.7 \%$ \\
2013 & $38,643,091$ & $28,588,284$ & $74.0 \%$ \\
2014 & $41,212,965$ & $30,631,124$ & $74.3 \%$ \\
2015 & $44,281,628$ & $32,355,606$ & $73.1 \%$ \\
2016 & $47,786,134$ & $34,132,976$ & $71.4 \%$ \\
2017 & $54,944,575$ & $36,619,551$ & $66.6 \%$ \\
2018 & $59,245,062$ & $38,932,977$ & $65.7 \%$ \\
\hline
\end{tabular}

[28]

described in Section 2.1 was used to assess the emissions levels for each transportation mode in each of the cities.

Total transport-related GHG emissions in Hanoi were 3,875 thousand $\mathrm{tCO}_{2 \mathrm{e}}$ in 2014. By 2020, these emissions increased by 35 percent (Table 6). The major GHG emission source is passenger motorcycles, which account for 53 percent of the total. Motorcycles also account for 68.3 percent of $\mathrm{PM}_{2.5}$ emissions and 83.5 percent of $\mathrm{NO}_{\mathrm{x}}$ emissions.

Total transport-related GHG emissions in Hai Phong were 312 thousand $\mathrm{tCO}_{2 \mathrm{e}}$ in 2014, with an increase of 53.7 percent by 2020. Motorcycles contribute 62 percent of these total emissions. In terms of $\mathrm{PM}_{2.5}$, motorcycles contribute 64.6 percent, and in terms of $\mathrm{NO}_{\mathrm{x}}$, motorcycles make up 71 percent (Table 7).

Total transport related GHG emissions in Da Nang were 236 thousand $\mathrm{tCO}_{2 \mathrm{e}}$ in 2014. By 2020, the emissions increase by 43.9 percent. Again, the major GHG emission source is motorcycles, at 72 percent. In terms of $\mathrm{PM}_{2.5}$, motorcycles account for 76.3 percent of the total, and in terms of $\mathrm{NO}_{\mathrm{x}}$, motorcycles account for 86.8 percent (Table 8 ).

In HCMC, total transport-related GHG emissions were 3,651 thousand $\mathrm{tCO}_{2 \mathrm{e}}$ in 2014, increasing by 38.3 percent by 2020 . Motorcycles contribute 68 percent of the total. In terms of $\mathrm{PM}_{2.5}$, motorcycles contribute 70.4 percent, and in terms of $\mathrm{NO}_{\mathrm{x}}$, motorcycles contribute 84.7 percent (Table 9).

Finally, in Can Tho, total transport-related GHG emissions were 181 thousand $\mathrm{tCO}_{2 \mathrm{e}}$ in 2014. These emissions

Table 6 WTW approach for GHG emissions in Hanoi, 2014-2020

\begin{tabular}{lllll}
\hline & 2014 (ths. $\mathrm{tCO}_{2 \mathrm{e}}$ ) & & $\begin{array}{l}\text { WTWCO } \\
\text { rate } 2014-2020(\%)\end{array}$ \\
\cline { 2 - 4 } & $\mathrm{WTWCO}_{2}$ & $\mathrm{PM}_{2.5}$ & $\mathrm{NOx}$ & \\
\hline MC & 2073 & 0.1 & 6.4 & 4.1 \\
MC taxi & 185 & 0.0 & 0.6 & 7.1 \\
PC & 667 & 0.0 & 0.7 & 7.4 \\
Taxi & 841 & 0.0 & 0.0 & 13.9 \\
Bus & 109 & 0.0 & 0.0 & 10 \\
\hline
\end{tabular}


Table 7 WTW approach for GHG emissions in Hai Phong, 20142020

\begin{tabular}{lllll}
\hline & \multicolumn{2}{l}{$2014\left(\right.$ ths. $\left.\mathrm{tCO}_{2 \mathrm{e}}\right)$} & $\begin{array}{l}\text { WTWCO } \\
\text { rate 2014-2020 (\%) }\end{array}$ \\
\cline { 2 - 4 } & $\mathrm{WTWCO}_{2}$ & $\mathrm{PM}_{2.5}$ & $\mathrm{NOx}$ & \\
\hline MC & 193 & 0.0 & 0.6 & 9.7 \\
MC taxi & 70 & 0.0 & 0.2 & 6.5 \\
PC & 25 & 0.0 & 0.0 & 26.7 \\
Taxi & 16 & 0.0 & 0.0 & 40.3 \\
Bus & 7 & 0.0 & 0.0 & 3.9 \\
\hline
\end{tabular}

Table 8 WTW approach for GHG emissions in Da Nang, 2014-2020

\begin{tabular}{lllll}
\hline & 2014 (ths. $\mathrm{tCO}_{2 \mathrm{e}}$ ) & & $\begin{array}{l}\text { WTWCO } \\
\text { rate } 2014-2020(\%)\end{array}$ \\
\cline { 2 - 4 } & $\mathrm{WTWCO}_{2}$ & $\mathrm{PM}_{2.5}$ & $\mathrm{NOx}$ & \\
\hline MC & 171 & 0.0 & 0.5 & 7.4 \\
MC taxi & 21 & 0.0 & 0.1 & 3.9 \\
PC & 13 & 0.0 & 0.0 & 38.0 \\
Taxi & 23 & 0.0 & 0.0 & 5.8 \\
Bus & 8 & 0.0 & 0.0 & 8.5 \\
\hline
\end{tabular}

Table 9 WTW approach for GHG emissions in HCMC, 2014-2020

\begin{tabular}{lllll}
\hline & $2014\left(\right.$ ths. $\left.\mathrm{tCO}_{2 \mathrm{e}}\right)$ & & $\begin{array}{l}\mathrm{WTWCO}_{2} \text { Growth } \\
\text { rate 2014-2020 }(\%)\end{array}$ \\
\cline { 2 - 4 } & $\mathrm{WTWCO}_{2}$ & $\mathrm{PM}_{2.5}$ & $\mathrm{NOx}$ & \\
\hline MC & 2,484 & 0.2 & 7.7 & 3.7 \\
MC taxi & 285 & 0.0 & 0.9 & 5.8 \\
PC & 468 & 0.0 & 0.5 & 4.7 \\
Taxi & 225 & 0.0 & 0.0 & 38.5 \\
Bus & 189 & 0.0 & 0.0 & 2.5 \\
\hline
\end{tabular}

Table 10 WTW approach for GHG emissions in Can Tho, 2014-2020

\begin{tabular}{lllll}
\hline & 2014 (ths. $\mathrm{tCO}_{2 \mathrm{e}}$ ) & & $\begin{array}{l}\mathrm{WTWCO}_{2} \text { Growth } \\
\text { rate 2014-2020 (\%) }\end{array}$ \\
\cline { 2 - 4 } & $\mathrm{WTWCO}_{2}$ & $\mathrm{PM}_{2.5}$ & $\mathrm{NOx}$ & \\
\hline MC & 2,484 & 0.2 & 7.7 & 3.7 \\
MC taxi & 285 & 0.0 & 0.9 & 5.8 \\
PC & 468 & 0.0 & 0.5 & 4.7 \\
Taxi & 225 & 0.0 & 0.0 & 38.5 \\
Bus & 189 & 0.0 & 0.0 & 2.5 \\
\hline
\end{tabular}

increase by 27.5 percent by 2020 . Once again, the major GHG emission source and local pollutants are motorcycles with 69 percent $\mathrm{WTWCO}_{2}, 71.1$ percent $\mathrm{PM}_{2.5}$ and 78.5 percent $\mathrm{NO}_{x}$, respectively (Table 10 ).
Table 11 Traffic fatality in five cities, 2014-2020

\begin{tabular}{llllll}
\hline & Hanoi & Hai Phong & Da Nang & HCMC & Can Tho \\
\hline 2014 & 609 & 92 & 98 & 725 & 81 \\
2015 & 579 & 87 & 93 & 689 & 77 \\
2016 & 594 & 89 & 88 & 804 & 81 \\
2017 & 585 & 89 & 69 & 717 & 101 \\
2018 & 544 & 85 & 56 & 694 & 110 \\
2019 & 508 & 78 & 54 & 641 & 105 \\
\hline
\end{tabular}

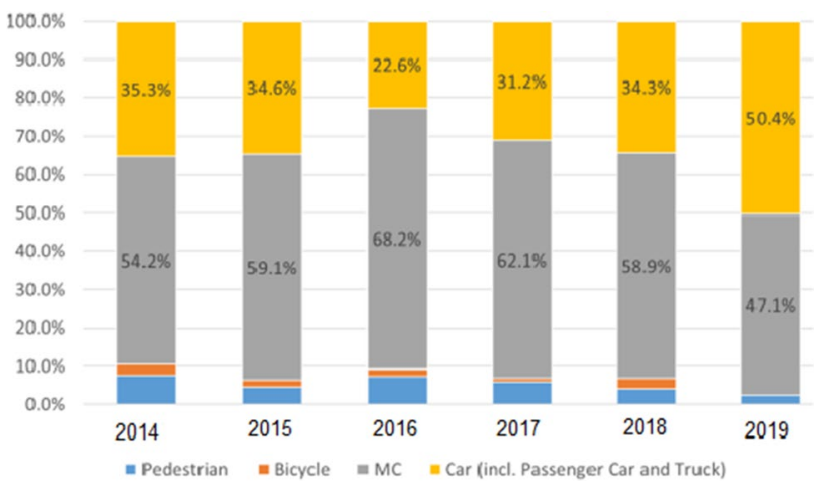

Fig. 3 Road fatalities by transportation mode in Hanoi, 2014-2019

\subsection{Safety}

Traffic fatalities are strongly associated with motorcycle travel in Vietnamese cities. Table 11 shows the number of traffic fatalities in the five cities targeted in this study for the years 2014 to 2019 . In 2019, of the 7,590 fatality cases at the national level, 1,386 were in the five cities.

Detailed fatal crash data for 2014-2019 for Hanoi can be used to illustrate the safety indicators. Fig. 3 shows that the highest risk of a fatal accident tends to be for motorcycle users. The percentage of road fatalities related to motorcycles varied between 47 percent and 68 percent over the years 2014-2019. This figure also reflects the fact of high mode share of motorcycle in the traffic flow. Also in this period of time, the percentage of road fatalities related to cars increased from 35.3 percent to 50.4 percent. The fatality of car is extremely high instead of low mode share of car.

NTSC, 2019b

\section{Policy Interventions and the Development of Scenarios}

\subsection{Policy Intervention}

In Vietnam, sustainable transport policies are guided by law, national strategies and action plans in four key categories: 
1) Sustainable Development, 2) Green Growth, 3) Climate Change and 4) Environmental Protection. Based on these national strategies and action plans, five key orientations of sustainable transport development are summarized in Table 12. In the updated Nationally Determined Contribution (NDC) under the Paris Agreement submitted in 2020, Vietnam committed to an $9 \%$ reduction in GHG emissions against a baseline projection by 2030 with domestic resources and this reduction can be increased by up to $27 \%$ with international support [16]. One of the measures identified in the NDC is a shift from private to public transport in transportation.

In this study, mobility, environment and safety indicators were estimated for two scenarios: BAU and improvement of public transport system. Changes in travel modes due to the improved public transport service were calculated by Eq. (4) and (5). However, due to the limitation of paper pages, only key outcomes were presented here.

\subsection{Development of scenarios}

\section{BAU scenario}

Mode share in baseline (BAU) in the period 2021-2030 was estimated according to Eq. (2) and (3). Based on economic growth assumption, the growth rate of six transportation modes were projected to increase at an annual average growth rate of 5.5 percent from 2020 to 2030 . The mode share relatively changes with growing motorization throughout the forecast period, the share of motorized vehicles increases somewhat compared to non-motorized vehicles: motorcycles accounts from 73.3 percent in Hanoi to 87.1 percent in Can Tho during the period. Private cars increased at an average of 6.42 percent. The results are illustrated in Table 13.

Table 12 Key orientations of sustainable transport development

\begin{tabular}{|c|c|c|}
\hline & Regulation & Orientation \\
\hline 1 & Law on environmental protection & $\begin{array}{l}\text { - Promulgation of incentive policies for the development of public transport } \\
\text { - Promulgation of incentive policies for transport vehicles using renewable energy, } \\
\text { vehicles with low fuel consumption or low emission } \\
\text { - Promulgation of roadmap for termination of fossil-fueled vehicles and vehicles caus- } \\
\text { ing environmental pollution }\end{array}$ \\
\hline 2 & Green growth strategy & $\begin{array}{l}\text { - Shifting share of fuel usage in transport sector (towards low-emission fuel) } \\
\text { - Reasonable and effective development of transport network and system } \\
\text { - Investment in public transport }\end{array}$ \\
\hline 3 & Sustainable Development Strategy & $\begin{array}{l}\text { - Control of emissions from transport vehicles } \\
\text { - Reduction of traffic accidents and fatalities } \\
\text { - Development of public transport, transport infrastructure and system in consideration } \\
\text { of climate change, the disabled, women, children and the elderly }\end{array}$ \\
\hline 4 & Climate Change Strategy & $\begin{array}{l}\text { - Development of public transport and control of private vehicles } \\
\text { - Usage of low-emission fuel and transport vehicles }\end{array}$ \\
\hline 5 & Environmental Protection Strategy & $\begin{array}{l}\text { - Control of environmental pollution by transport activities } \\
\text { - Control of emissions of motorcycles } \\
\text { - Implementing a roadmap for applying emission standards to motorized road vehicles } \\
\text { - Encouraging clean-energy and renewable-energy transport vehicles }\end{array}$ \\
\hline
\end{tabular}

Table 13 Growth rates and mode share based on transport and economic data under BAU, $2030(\%)$

\begin{tabular}{|c|c|c|c|c|c|c|}
\hline Growth rate & $\mathrm{BC}$ & $\mathrm{MC}$ & MC taxi & Car & Taxi & $\mathrm{PT}$ \\
\hline Hanoi & -2.2 & -1.1 & 1.2 & 11.1 & 4.5 & 7.4 \\
\hline Hai Phong & 2.8 & 0.7 & 6.1 & 6.4 & 5.8 & 6.9 \\
\hline Da Nang & 3.7 & 1.3 & 7.4 & 9.7 & 7.8 & 1.9 \\
\hline $\mathrm{HCMC}$ & -5.3 & -0.1 & 2.8 & 13.3 & 6.3 & 5.7 \\
\hline Can Tho & 5.8 & 4.3 & 13.7 & 7.8 & 11.0 & 17.3 \\
\hline Mode share & $\mathrm{BC}$ & $\mathrm{MC}$ & MC taxi & Car & Taxi & PT \\
\hline Hanoi & 2.5 & 73.3 & 2.8 & 6.4 & 6.4 & 8.6 \\
\hline Hai Phong & 2.8 & 79.4 & 7.3 & 7.3 & 2.7 & 0.5 \\
\hline Da Nang & 1.9 & 86.9 & 2.5 & 7.5 & 0.8 & 0.4 \\
\hline HCMC & 2.1 & 81 & 3.2 & 3.4 & 5.9 & 4.4 \\
\hline Can Tho & 1.9 & 87.1 & 2.5 & 7.5 & 0.4 & 0.6 \\
\hline
\end{tabular}


Table 14 Generalized cost parameters by mode, Hanoi

\begin{tabular}{llllll}
\hline Mode & VOT $(\$ /$ hour $)$ & VOC $(\$ / \mathrm{km})$ & Fare $(\$)$ & $\begin{array}{l}\text { Parking cost } \\
(\$ / \text { trip })\end{array}$ & $\begin{array}{l}\text { Average occu- } \\
\text { pancy (person/ } \\
\text { vehicle) }\end{array}$ \\
\hline Bike & 0.658 & 0.0046 & & 0.041 & 1.1 \\
MC & 0.945 & 0.0299 & & 0.143 & 1.45 \\
MC taxi & 0.823 & & 1.304 & & 1.5 \\
Car & 1.723 & 0.0705 & & 0.614 & 1.7 \\
Taxi & 1.402 & & 5.165 & & 1.7 \\
Bus & 0.525 & & 0.331 & & 25 \\
BRT & 0.753 & & 0.331 & & 35 \\
Metro & 0.788 & & 0.596 & & 40 \\
\hline
\end{tabular}

Table 15 Estimated parameters of mode share model

\begin{tabular}{llll}
\hline Mode & \multicolumn{2}{l}{ Parameter } & Correlation \\
\cline { 2 - 3 } & $\alpha$ & $\beta$ & \\
\hline Bike & 0.598 & 1.814 & 0.87 \\
MC & -0.842 & -0.878 & 0.97 \\
MC taxi & 0.829 & -1.907 & 0.97 \\
Car & 0.139 & 2.950 & 0.62 \\
Taxi & -2.030 & 1.970 & 0.60 \\
Bus & 0.513 & 3.052 & 0.64 \\
BRT & 0.856 & 1.212 & 0.63 \\
Metro & 0.877 & 1.555 & 0.63 \\
\hline
\end{tabular}

\section{Mode share under public transport system scenario}

Parameters of generalized travel cost function and mode share were estimated with the logistic models. The transportation modes were categorized into eight groups: bike, motorcycle, motorcycle taxi, private car, taxi, bus, BRT, and metro in Hanoi and Hochiminh City, while the other cities were explained by six transportation modes with the absence of BRT and metro. Tables 14 and 15 show an example of parameters in case of Hanoi. Generalized cost parameters by modes in four remaining cities were not described due to the paper length limitation.

Table 16 summarize the share of travel modes in the five cities in 2030 for the public transport improvement scenario.
Hanoi and HCMC differ from the other cities included in the study in terms of population, urban size, availability of transport infrastructure, and travel mode share. In 2014, in Hanoi, 6.4 percent of the total trips were made by bus, as compared to 4.4 percent in HCMC and 0.5 percent in other cities. This results in substantial differences in the impacts of public transport investment and service quality, including investment of BRT and metro lines, on travel mode shares across the five cities. As shown in Table 16, improving public transport in Hanoi is likely to increase the modal share of public transport to 25 percent in 2030, as compared to 11.2 percent in 2030 in HCMC. The modal share of buses in the remaining cities is in the range of 3.7-7 percent by 2030 .

\subsection{Emissions}

The changes in emissions in the five cities are indicated in Figs. 4, 5, 6, 7 and 8. As shown, improving public transport would result in a reduction of 21.11 percent of transport emissions by 2030 in Hanoi, 12.5 percent in Hai Phong, 17.37 percent in Da Nang, 9.75 percent in HCMC, and 15.21 percent in Can Tho. The differences here are due to the heterogeneous modal variation across cities. Among the cities, Hanoi has the largest shift from private vehicles to public transport, and thus the reduction in emissions is relatively large.
Table 16 Estimated share of travel modes under improvement, 2030

\begin{tabular}{lllllll}
\hline & BC & MC & MC taxi & Car & Taxi & PT \\
\hline Hanoi & 1.5 & 60.9 & 1.8 & 5.4 & 5.4 & 25.0 \\
Hai Phong & 6.8 & 74.6 & 4.9 & 7.3 & 2.7 & 3.7 \\
Da Nang & 1.8 & 81.5 & 3.9 & 5.3 & 2.5 & 5.0 \\
HCMC & 4.3 & 70.3 & 3.8 & 3.4 & 7.0 & 11.2 \\
Can Tho & 1.8 & 77.8 & 3.9 & 6.3 & 3.2 & 7.0 \\
\hline
\end{tabular}




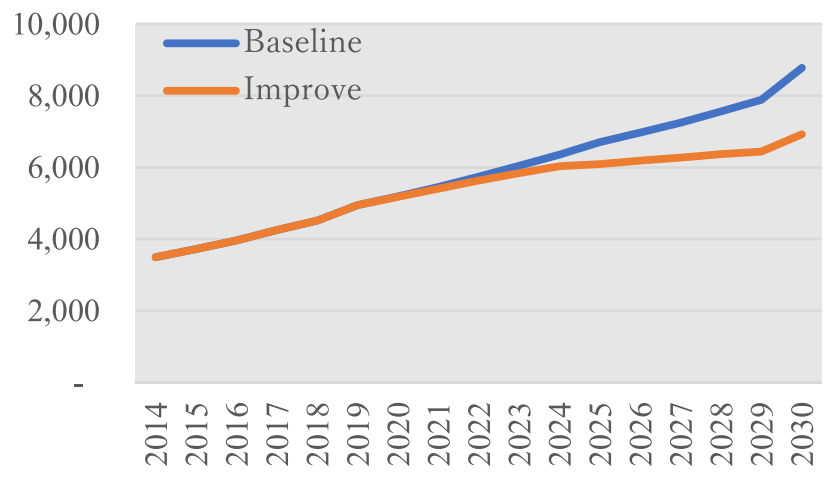

Fig. 4 Scenarios of GHG Emissions Hanoi, 2014-2020, WTW approach

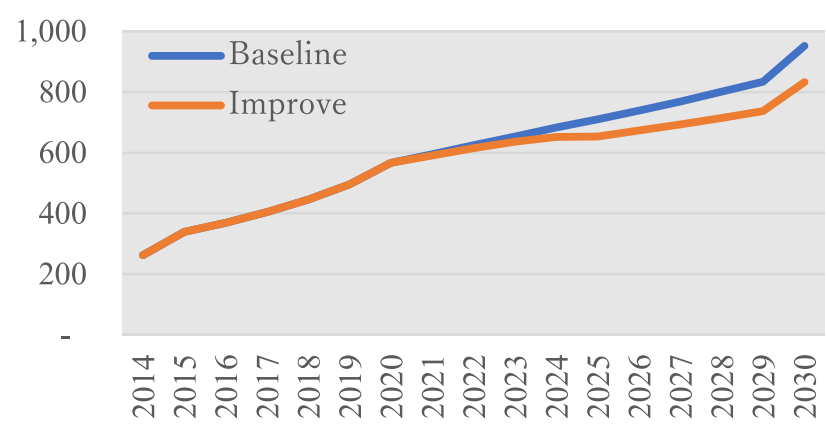

Fig. 5 Scenarios of GHG Emissions Hai Phong, 2014-2020, WTW approach, Da Nang, 2014-2020, WTW approach

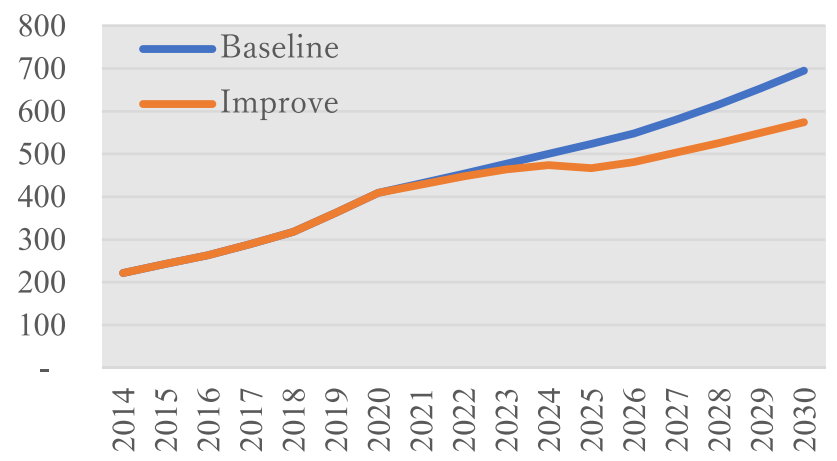

Fig. 6 Scenarios of GHG Emissions Da Nang, 2014-2020, WTW approach

\subsection{Safety}

Total fatalities due to road crashes were assumed to be associated with number of motorcycles and cars. Using country level data, a model for projecting fatal crashes using Eq. (9) was constructed. Table 17 gives the projected fatalities based on increases in the number of motorcycles and cars. The model shows that if the other variables are held constant, a 1 percent motorcycle rate increase will increase the traffic

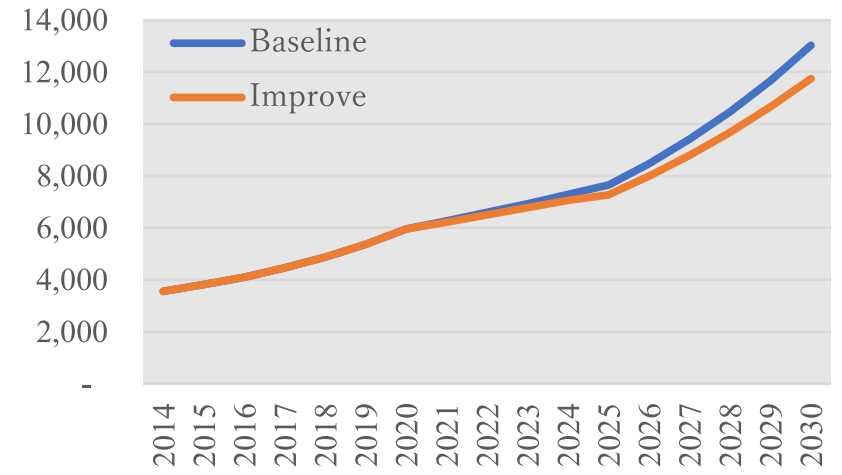

Fig. 7 Scenarios of GHG Emissions HCMC, 2014-2020, WTW approach

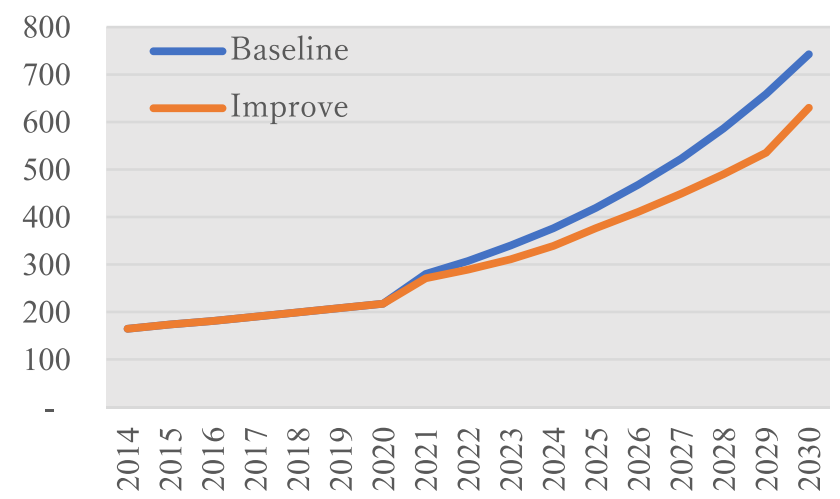

Fig. 8 Scenarios of GHG Emissions Can Tho, 2014-2020, WTW approach

Table 17 Regression coefficients for fatality rate during the period 1990-2019

\begin{tabular}{lll}
\hline Variable & Value & P-value \\
\hline Constant $\left(\mathrm{b}_{1}\right)$ & 4.791 & 0.00 \\
Motorcycle per 1,000 inhabitants $\left(\mathrm{b}_{2}\right)$ & 1.047 & 0.00 \\
Car per 1,000 inhabitants $\left(\mathrm{b}_{2}\right)$ & -0.875 & 0.00 \\
Adjusted $\mathrm{R}^{2}$ & .976 & \\
Standard error & 0.078 & \\
$\mathrm{~F}$ & 521.598 & 0.000 \\
\hline
\end{tabular}

fatality rate by 1.047 . The results of the model were applied to calculate the fatality rate at the city level.

Figure 9 shows the percentage change from the existing situation in the five cities. As per the estimates, there is a significant decrease in the total number of traffic fatalities with the improvement scenario. Provision of public transport and improvement of service quality is likely to result in an increase in the passenger-km traveled by bus and decrease the passenger-km traveled by motorcycle. Furthermore, the provision of improved bus infrastructure is likely to 


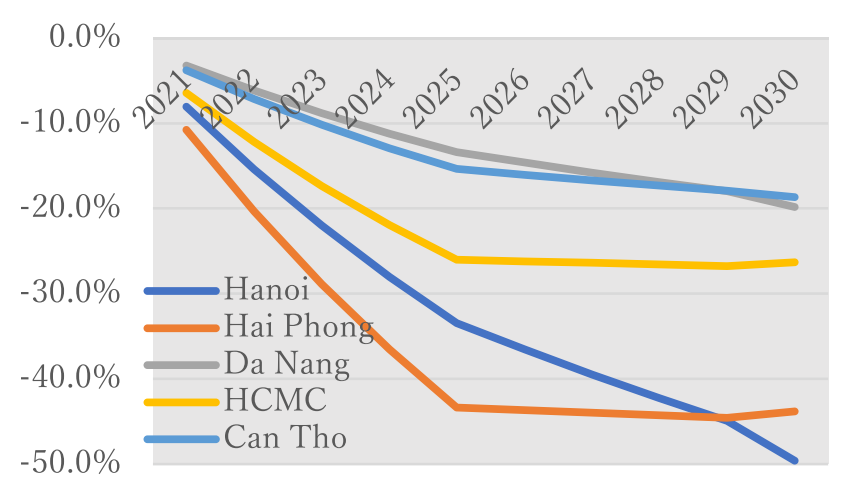

Fig. 9 Percentage change in road fatalities in the five cities

reduce conflict between buses and other road users, such as bikes, motorcycles and cars. The risk to road users in Hanoi decreases by 49.6 percent by 2030 , while in Hai Phong, it decreases by 43.8 percent. The risks in Can Tho, Da Nang and HCMC decrease by 18.7 percent, 19.8 percent, and 26.3 percent, respectively.

\section{Conclusion}

Clearly, motorcycle use is well entrenched in the cities of Vietnam. Motorcycles have attributes that make them attractive to residents and meet the key mobility requirements of most people. However, they offer poor user safety and polluted air. New social challenges owing to climate change, urbanization, globalization but also cultural and technical developments impose great challenges for city planners.

Public transport is the most desirable mode of transportation for meeting the travel demands of city residents, having the least adverse effects on the environment and traffic safety. Improving public transport offers better safety and comfort to users and is thus likely to bring about a shift from motorcycle use to the use of public transportation.

This study examined differences in the mode share outcome among cities. Public transport investment interest might produce some differences in the way how citizens choose travel mode. This study is particularly relevant in the context of significant policy interest and investment over the last decade aiming at improving public transport in Vietnam. Findings from this study confirm that improvements in the public transport should remain the major focus of the urban development programmes.

In this study, transportation mode shares, emissions and traffic safety in five major Vietnamese cities were examined. Detailed analysis of trip characteristics in the five cities showed that motorcycle trips were dominant. The results of a scenario analysis revealed the substantial benefits of improving public transport. Based on model projections, by improving public transport (i.e., expansion of bus systems, expansion of BRT systems, and deployment of metro systems), the modal share of public transport increased in all five cities, leading to lower fuel consumption and a reduction in equivalent $\mathrm{CO}_{2}$ emissions. Traffic safety was also measurably improved, as improving public transport facilities and reducing the use of motorcycles leads to fewer traffic fatalities. The magnitude of the impact differed among the five cities, since the potential shift to public transport from motorcycles is not uniform.

\subsection{Policy interventions}

These findings may provide several important implications for transportation policy and public transport planning in Vietnamese cities and perhaps in other cities with high motorcycle concentrations. The modal share from surveys showed that it is crucial to have a systematic and coherent strategy for developing the public transport system.

Public transport measures must be facilitated by both traffic management policies and land use plans. In particular, transport activities always encourage motorcycle use. Therefore, a connection between motorcycles and public transport should be further considered in the development of the overall transport strategy. Motorcycle and motorcycle taxis may provide high levels of local accessibility for short trips and feeder services to public transport, and they perform a valid and valuable function; thus, a careful balance of motorcycle access and use may be required, and the role of motorcycle should be recognized in future public transport planning. In the meantime, urban land use should be integrated with public transport development by increasing commercial and service activities near public transport stations to maximize the benefits of public transport.

Finally, considering the strong connection between individual perception and travel behaviors, the bus network needs to expand to ensure network coverage and accessibility for people who are living in suburban. Moreover, greater effectiveness can be achieved by improving the accessibility and safety of public transport.

\subsection{Limitations}

The scope of this study was somewhat limited. In terms of data collected, the data used in this study is self-reported travel information which has some limitations such as exaggeration and social desirability bias [25]. Out of a range of low-carbon mobility measures, the impact assessment of public transport measure alone does not fully reflect the local government's concerns in addressing the challenges related to safety and emissions. In addition, the paper did not take into account the impact of COVID-19. Further research is necessary to evaluate all policy packages to achieve higher reductions in transport emissions. 
Conflict of Interest The authors declare that they have no conflict of interest.

\section{References}

1. Adam, C., and Susan, S. Planning for mobility. The American Planning Association; Berkeley, CA, USA: 2018.

2. Ahmed, S., Adnan, M., Janssens, D., Wets, G.: A route to school informational intervention for air pollution exposure reduction. Sustain. Cities Soc. 53, 101965 (2020). https://doi.org/10.1016/j. scs.2019.101965

3. Barter, P.A.: Transport, urban structure and "lock-in" in the Kuala Lumpur Metropolitan Area. Int. Develop. Plann. Rev. 26, 1-24 (2004)

4. Beimborn, E., Greenwald, M., Jin, X. Accessibility, connectivity, and captivity Transp. Res. Rec. (2003), pp. 1-9

5. Brakewood, C., Barbeau, S., Watkins, K.: An experiment evaluating the impacts of real-time transit information on bus riders in Tampa, Florida. Transp. Res. Part A Policy Pract. 69, 409-422 (2014). https://doi.org/10.1016/j.tra.2014.09.003

6. Brazil, W., Kallbekken, S., Sælen, H., Carroll, J.: The role of fuel cost information in new car sales. Transp. Res. Part D Transp. Environ. 74, 93-103 (2019). https://doi.org/10.1016/j.trd.2019. 07.022

7. Bray, D.J. and Holyoak, N. Motorcycles in developing Asian cities: A case study of Hanoi. 37th Australasian Transport Research Forum, Sydney, 2015.

8. Breusch, T.S.: Testing for Autocorrelation in Dynamic Linear Models. Australian Economic Papers. 17, 334-355 (1978). https:// doi.org/10.1111/j.1467-8454.1978.tb00635.x

9. Can Tho People Committee (Can Tho PC) n.d.. Project of enhancing public passenger transport in combination with controlling the use of private vehicles in traffic in the area.; reasonably control and regulate transport mode into the center of Can Tho city

10. Chu, M.C., Nguyen, L.X., Ton, T.T., Huynh, N., 2019. Assessment of motorcycle ownership, use, and potential changes due to transportation policies in Hochiminh City, Vietnam. J. Transp. Eng., Part A: Systems, 145(12): 05019007.

11. Da nang People Committee (Da Nang PC). General planning of Da Nang city to 2030 with a vision to 2045. 2018.

12. Fujii, S., and Van, H.T. Psychological determinants of the intention to use the bus in Hochiminh City. Journal of Public Transportation, Vol. 12, No. 1, 2009.

13. Gärling, T., Fujii, S.: Travel behavior modification: Theories, methods, and programs. In: Kitamura, R., Yoshio, T., Yamamoto, T. (eds.) The Expanding Sphere of Travel Behavior Research. 1st ed. Emerald Group Publishing Limited, pp. 97-128. UK, Bingley (2009)

14. Giuliano, G.: Low income, public transit, and mobility. Transp. Res. Rec. 1927, 63-70 (2005)

15. Godfrey, L. G. Testing Against General Autoregressive and Moving Average Error Models when the Regressors Include Lagged Dependent Variables. Econometrica. 46:1293-1301. JSTOR 1913829. 1978

16. Government of Vietnam (GOV). Updated Nationally Determined Contribution (NDC), 2020.

17. Hanoi People Committee (Hanoi PC). Project on Strengthening the management of road vehicles in order to reduce traffic congestion and environmental pollution in Hanoi city, period 2017-2020 with a vision to 2030. Project Report, 2017

18. He, D., Liu, H., He, K., Meng, F., Jiang, Y., Wang, M., Zhou, J., Calthorpe, P., Guo, J., Yao, Z., Wang, Q.: Energy use of and $\mathrm{CO}_{2}$ emissions from China's urban passenger transportation sector carbon mitigation scenarios upon the transportation mode choices. Transp. Res. Part A: Policy Pract. 53, 43-67 (2013)

19. Hochiminh City Department of Transport (HCMC DOT). Development of transportation modelling. 2018

20. Huyn, D.T., Gómez-Ibáñez, J. Chapter 13: Vietnam D. Pojani (Ed.), The Urban Transport Crisis in Emerging Economies, Springer Science+Business Media, New York, NY (2017), pp. 267-282

21. JICA. The Study on Urban Transport Master Plan and Feasibility Study in Hochiminh Metropolitan Area (HOUTRANS), 2003.

22. JICA. The Comprehensive Urban Development Programme in Hanoi Capital City of the Socialist Republic of Vietnam (HAIDEP), 2005.

23. JICA: Data Collection Survey on Railways in Major Cities in Vietnam. Part I, Hochiminh City (2015a)

24. JICA: Data Collection Survey on Railways in Major Cities in Vietnam. Part II, Hanoi (2015b)

25. Langenbucher, J., Merrill, J.: The validity of self-reported cost events by substance abusers: limits, liabilities, and future directions. Eval. Rev. 25(2), 184-210 (2001)

26. Lachapelle, U., Frank, L., Saelens, B.E., Sallis, J.F., Conway, T.L.: Commuting by public transit and physical activity: where you live, where you work, and how you get there. J. Phys. Activ. Health. 8, S72-S82 (2011)

27. Liu, F., Yun, M., Liu, G. Will motorcyclist shift to bus or car in commuting: a case study of Zhongshan, China. In: Proceedings of Transportation Research Board $95^{\text {th }}$ Annual Meeting, Washington, D.C., January 2016.

28. Ministry of Transport (MOT). Development of traffic safety strategy for motorcycle and action plan: A Vietnam starts. Final Report. Code: TRN/FAC/12/006/REG. 2020

29. NTSC. Statistics of national traffic accidents, 2019

30. NTSC. Motorcycle and car statistics from 1990 to 2020, 2021

31. Nguyen, M.B. "Vietnam country report" in Han, P. and S. Kimura (eds.), Energy Outlook and Energy Saving Potential in East Asia 2020, Jakarta: ERIA, pp. 281-299. 2021

32. Nguyen, N.T., Miwa, T., Morikawa, T.: Response to the planned public transport system in Ho Chi Minh City: analysis of latent classes. Clean Technologies and Environmental Policy. 21, 19251935 (2019)

33. Nguyen, N.T., Miwa, T., Morikawa, T.: Switching to public transport modes for commuting trips: considering latent motivations in Ho Chi Minh City. Asian Transport Studies. 5(1), 117-136 (2018)

34. OECD. OECD Urban Policy Reviews: Viet Nam, OECD Urban Policy Reviews. OECD (2018)

35. https://doi.org/10.1787/9789264286191-en

36. Susan, S., Adam, C., Michael, R., Emily, F., Richard, D., Aqshems, N. Shared Mobility Policy Playbook. Institute of Transportation Studies; Berkeley, CA, USA: 2019

37. Taylor, M.: Voluntary travel behavior change programs in Australia: The carrot rather than the stick in travel demand management. Int. J. Sustain. Transp. 1, 173-192 (2007). https://doi.org/ 10.1080/15568310601092005

38. Taniguchi, A., Suzuki, H., Fujii, S.: Mobility management in Japan: Its development and meta-analysis of travel feedback programs (TFPs) Transp. Res. Rec. J. Transp. Res. Board. 2021, 100-109 (2007). https://doi.org/10.3141/2021-12

39. Truong, T.M.T., Ngoc, A.M.: Parking behavior and the possible impacts on travel alternatives in motorcycle-dominated cities. Transport Research Procedia. 48, 3469-3485 (2019)

40. Tuan, V.A.. Mode choice behavior and modal shift to public transport in developing countries - the case of Hanoi city. Journal of the Eastern Asia Society for Transportation Studies, Vol. 11, 2015.

41. Vietnam Register. Vehicle fleet by fuel type. 2020 
42. White, H. A Heteroskedasticity-Consistent Covariance Matrix Estimator and a Direct Test for Heteroskedasticity. Econometrica. 48 (4): 817-838. CiteSeerX 10.1.1.11.7646. https://doi.org/ 10.2307/1912934.JSTOR1912934, 1980.

43. World Bank. Feasibility study for the Da Nang sustainable city development project. Component 2 - BRT system. 2012

44. World Bank. The project "Sustainable Urban Public Transport and Central Area Traffic Management Study for Can Tho City". 2020

45. Xiong, C., Shahabi, M., Zhao, J., Yin, Y., Zhou, X., Zhang, L.: An integrated and personalized traveler information and incentive scheme for energy efficient mobility systems. Transp. Res. Part C Emerg. Technol. 113, 57-73 (2020). https://doi.org/10.1016/j.trc. 2019.04.025

46. Xu, J.: Authoritarian policing with Chinese characteristics: a case study of motorcycle ban in the Pearl River Delta. Crime Law Social Change. 61(4), 439-460 (2014)

Publisher's Note Springer Nature remains neutral with regard to jurisdictional claims in published maps and institutional affiliations.

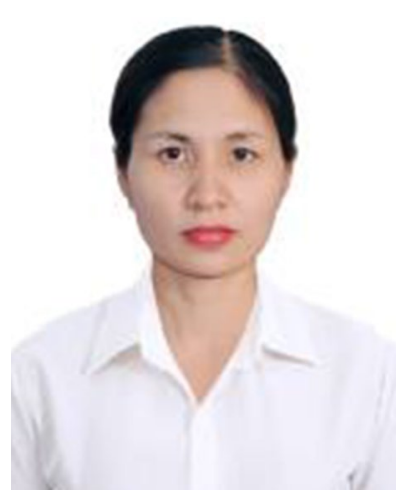

An Minh Ngoc is lecturer at the University of Transport and Communications and Associate Researcher at Kochi University of Technology. She gained her doctorate from TU Darmstadt, ermany, in 2015. Her majors are transport planning and traffic management.

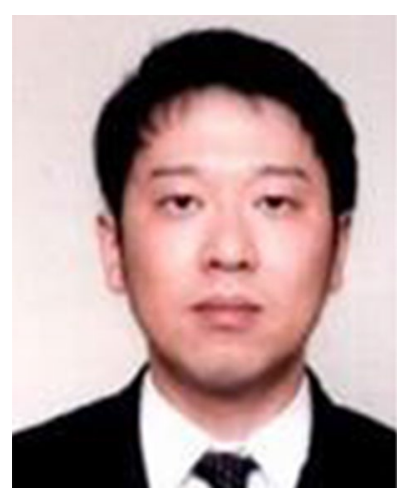

Hiroaki Nishiuchi is an Associate Professor at Kochi University of Technology. He received his doctor of Engineering degree from the University of Tokyo in 2009. His research interests include traffic engineering and transportation planning

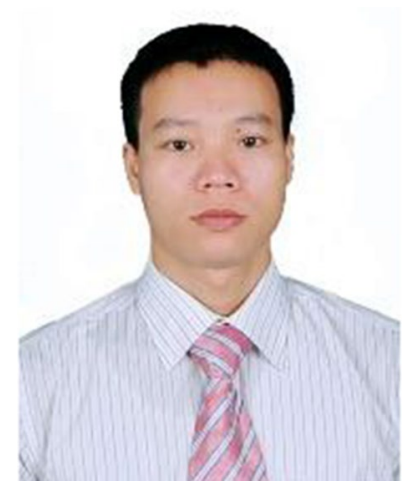

Nguyen Van Truong is a lecturer at the University of Transport and Communication and researcher at Tokyo Metropolitan University. His research interest includes travel behavior, transport engineering, and transport policy.

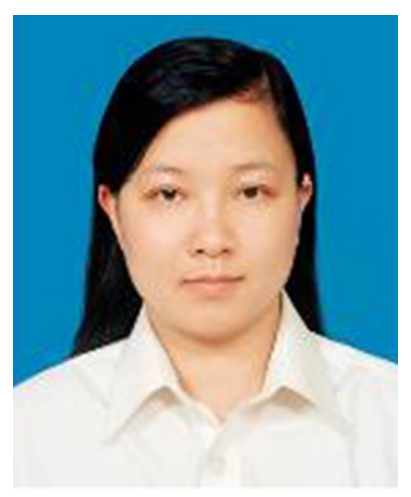

Le Thu Huyen is a lecturer in University of Transport and Communications, Vietnam. She gained her doctorate from TU Darmstadt, Germany, in 2009. She specializes in traffic engineering, traffic safety and logistics with many contributions in scientific research and projects in related fields. 